\title{
Investigation of different piston ring curvatures on lubricant transport along cylinder liner in large two-stroke marine diesel engines
}

\author{
Overgaard, H; Klit, P; Vølund, A
}

Published in:

Proceedings of the Institution of Mechanical Engineers, Part J: Journal of Engineering Tribology

Link to article, DOI:

10.1177/1350650117744100

Publication date:

2018

Document Version

Peer reviewed version

Link back to DTU Orbit

Citation (APA):

Overgaard, H., Klit, P., \& Vølund, A. (2018). Investigation of different piston ring curvatures on lubricant transport along cylinder liner in large two-stroke marine diesel engines. Proceedings of the Institution of Mechanical Engineers, Part J: Journal of Engineering Tribology, 232(1), 85-93 . https://doi.org/10.1177/1350650117744100

\section{General rights}

Copyright and moral rights for the publications made accessible in the public portal are retained by the authors and/or other copyright owners and it is a condition of accessing publications that users recognise and abide by the legal requirements associated with these rights.

- Users may download and print one copy of any publication from the public portal for the purpose of private study or research.

- You may not further distribute the material or use it for any profit-making activity or commercial gain

- You may freely distribute the URL identifying the publication in the public portal 


\title{
Investigation of Different Piston Ring Curvatures on Lubricant Transport along Cylinder Liner in Large Two-Stroke Marine Diesel Engines.
}

\author{
H. Overgaard ${ }^{1}$, P. Klit ${ }^{1}$ and A. Vølund ${ }^{2}$
}

\begin{abstract}
A theoretical investigation of the hydrodynamic lubrication of the top compression piston ring in a large two-stroke marine diesel engine is presented. The groove mounted piston ring is driven by the reciprocal motion of the piston. The ring shape follows a circular geometry and the effect of changes in radii is analysed.

A numerical model based on the finite difference method in 1D has been developed for solving Reynolds equation in combination with the load equilibrium equation together with flow continuity between the piston ring surface and liner for analysis of the lubricant transport.

The cyclic variation throughout one stroke is presented for the minimum film thicknesses at different interesting locations of the piston ring surface together with the friction and the pressure distribution history. The aforementioned parameters have been investigated numerically. The numerical results are presented and discussed.
\end{abstract}

\section{Keywords}

lubricant transport, piston ring lubrication, perturbation of Reynolds equation, flow continuity, lubricant starvation.

\section{Introduction}

Piston ring lubrication has previously been studied by numerous authors e.g. numerical schemes were developed to solve Reynolds equation simultaneously with the load equilibrium equation for one cycle in [1], a parametric study of the friction between piston rings and liner in [2], a theoretical study of piston ring lubrication for fully flooded and starved conditions in, respectively, [3] and [4], a performance analysis of a piston ring pack by studying key parameters such as oil consumption, blow-by/blow-back, power loss etc. in [5], the effect of surface roughness on lubrication between a piston ring and cylinder liner in [6], a theoretical analysis of the twin-land of oil-control piston ring in [7] as well as a theoretical modeling of cavitation in piston ring lubrication in [8]. The studies cover a wide spectrum of piston ring tribology including hydrodynamic and mixed lubrication, cavitation and oil transport.

A study of the friction loss of a large two-stroke marine diesel engine, a 4T50MX located in the research centre of MAN Diesel \& Turbo SE, Copenhagen, has been performed by [9]. It has been concluded that the piston ring pack, consisting of four piston rings, counts for approximately 60 $\%$ of the total mechanical loss [10].

Large two-stroke marine diesel engines are lubricated somewhat differently than a conventional trunk engine. In large marine engines the cylinder lubricant is injected at a discrete position on the liner. It is supplied at every $2 \mathrm{nd}$, 3rd or maybe every 10 th stroke at a discrete time and location.
The lubricant is after use lost as it either ends up in the scavenge area or is combusted. Therefore it is crucial to understand the lubricant transport between the injections in order to achieve an adequate injection volume. If it is too small the piston rings will dry out leading to increased asperity contact, abrasion and increased friction as well as power loss and inadequate sealing between the combustion chamber gas and scavenging area. If the quantity is too large the lubricant is transported into the scavenging area or end up in the combustion chamber where it is either combusted or evaporated.

From both an economic and environmental point of view it would be reasonable to reduce the amount of cylinder lubricant as it is, if combusted, an expensive fuel and contains several polluting additives.

In order to determine the adequate amount of lubricant one must understand and be able to predict the lubricant transport mechanisms. This paper will present a method of modeling

\footnotetext{
${ }^{1}$ Technical University of Denmark, Dept. of Mech. Engineering, Nils Koppels Allé 404, 2800 Kgs. Lyngby, Denmark.

${ }^{2}$ MAN Diesel \& Turbo SE, Teglholmsgade 41, 2450 Copenhagen SV, Denmark.
}

\section{Corresponding author:}

Hannibal Overgaard, Technical University of Denmark, Department of Mechanical Engineering, Nils Koppels Allé 404, 2800 Kgs. Lyngby, Denmark.

Email: hcover@mek.dtu.dk 


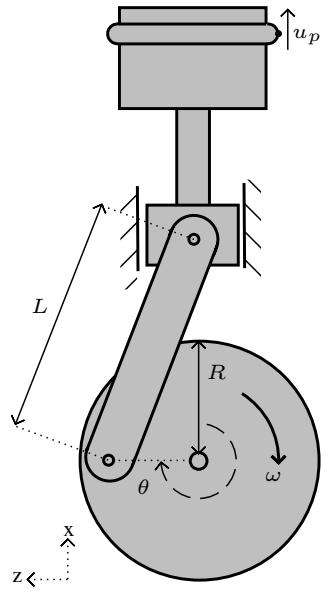

Figure 1. Crankshaft / connecting rod / crosshead / piston assembly.

the transport throughout one stroke with both fully flooded and starved conditions. The effect of changes in piston ring radii will be presented and discussed.

\section{Method}

\section{Reynolds equation}

The piston ring package normally consists of several rings. This study only addresses one ring. Thereby eliminating phenomenas between the rings. Reynolds equation is used for calculating the hydrodynamic film pressure distribution between the top compression piston ring and cylinder liner. It can be seen in Equation 1 for one-dimensional pressure distribution in $\mathrm{x}$-direction where the pressure gradient in the circumferential direction is neglected.

$$
\frac{\partial}{\partial x}\left(\frac{\rho h^{3}}{12 \eta_{0}} \frac{\partial p}{\partial x}\right)=\tilde{u} \frac{\partial(\rho h)}{\partial x}+\frac{\partial(\rho h)}{\partial t}
$$

Where $\rho$ is the density of the lubricant, $h$ the oil film thickness, $\eta_{0}$ the viscosity of the lubricant, $p$ the lubricant pressure, $\tilde{u}$ the relative velocity and $t$ the time.

Reynolds equation can be rewritten into Equation 2 with only the piston moving under consideration of the lubricant being Newtonian, isoviscous, incompressible and with constant density.

$$
\frac{\partial}{\partial x}\left(h^{3} \frac{\partial p}{\partial x}\right)=6 u_{x} \eta_{0} \frac{\partial h}{\partial x}+12 \eta_{0} \frac{\partial h}{\partial t}
$$

Where $h$ the oil film thickness, $\eta_{0}$ the viscosity of the lubricant, $p$ the lubricant pressure, $u_{x}$ the liner velocity and $t$ the time.

The geometrical relationship between the angular velocity of the crankshaft, $\omega$, crank angle degree, $\theta$, and piston velocity, $u_{p}$, is illustrated in Figure 1 and Equation 3.

$$
u_{p}=\omega\left(R \sin (\theta)+\frac{R^{2} \sin (\theta) \cos (\theta)}{\sqrt{L^{2}-R^{2} \sin ^{2}(\theta)}}\right)
$$

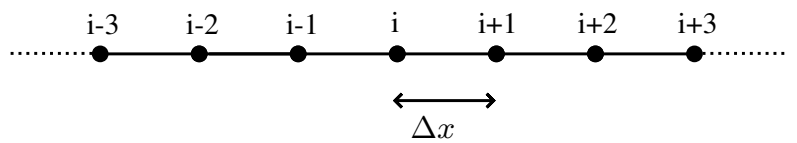

Figure 2. FDM scheme, central difference.

Where $\omega$ is the crankshaft angular velocity, $R$ the crankshaft radius, $\theta$ the crank angle degree and $L$ the connecting rod length.

\section{Film pressure distribution}

The central finite difference method (FDM) has been used for deriving an approximate solution to Reynolds equation. The FDM-scheme is shown in Figure 2.

Reynolds equation can be rewritten by FDM into the difference equation seen in Equation 4 from [11].

$$
\begin{aligned}
& \underbrace{\frac{h_{i+1 / 2}^{3}}{\Delta x^{2}}}_{A_{i}} p_{i+1}+\underbrace{\frac{h_{i-1 / 2}^{3}}{\Delta x^{2}}}_{B_{i}} p_{i-1} \underbrace{-\frac{h_{i+1 / 2}^{3}+h_{i-1 / 2}^{3}}{\Delta x^{2}}}_{C_{i}} p_{i} \\
= & \underbrace{6 u_{x} \eta_{0} \frac{h_{i+1}-h_{i-1}}{2 \Delta x}+12 \eta_{0} \frac{h_{i}-h_{i, o l d}}{\Delta t}}_{f_{i}}+\operatorname{error}\left(\Delta x^{3}\right)
\end{aligned}
$$

The equation can be solved by solving the linear equation system shown in Equation 5 with respect to the film pressure distribution. The pressure is afterwards imposed with Reynolds boundary conditions with open-end cavitation suggested by [12].

$$
\begin{array}{r}
\underbrace{\left[\begin{array}{cccccc}
C_{1} & A_{1} & & & & \\
B_{2} & C_{2} & A_{2} & & & \\
& B_{3} & C_{3} & A_{3} & & \\
& & \cdot . & . . & . . & \\
& & & B_{n x} & C_{n x} & A_{n x}
\end{array}\right]}_{D} \underbrace{\left[\begin{array}{c}
p_{1} \\
p_{2} \\
p_{3} \\
. \cdot \\
p_{n x}
\end{array}\right]}_{p_{0}}=\underbrace{\left[\begin{array}{c}
f_{1} \\
f_{2} \\
f_{3} \\
. \\
f_{n x}
\end{array}\right]}_{f_{0}} \\
\Leftrightarrow p_{0}=D / f_{0}
\end{array}
$$

Where $A_{i}, B_{i}, C_{i}$ and $f_{i}$ are the coefficients from Equation 4 and $p_{0}$ the pressure distribution.

\section{Force equilibrium}

A free body diagram (FBD) of the piston ring with the forces acting on it is seen in Figure 3. The piston ring is surrounded by the liner at one side and the piston at the other side. The gas pressure above and behind, $p_{1, \text { gas }}$, and below, $p_{2, g a s}$, exert normal pressures on the piston ring. The elastic spring tension of the piston ring, $p_{s p}$, is represented by a normal pressure on the rear side and is typically in order of $10^{5} \mathrm{~Pa}$ [13]. Furthermore the piston ring is exerted to the hydrodynamic pressure of the lubricant. For this study the gas pressures have been neglected even though their contribution are much larger than the spring tension force 


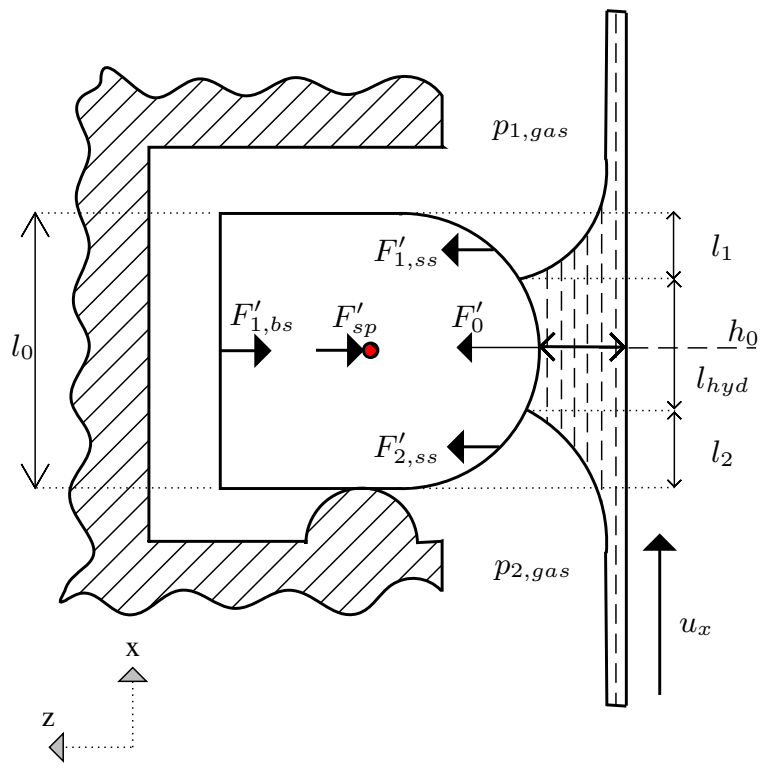

Figure 3. FBD of piston ring.

and would have a significant influence on the results. It is done in order to simplify the numerical study and clearly extract the influence of main the parameter investigated i.e. the curvature of the piston ring.

It is assumed that the ring only has one degree of freedom i.e. radial movement in z-direction. Axial movement of the ring in $\mathrm{x}$-direction is not considered. Both the radial and axial movement could pump lubricant, e.g. by ring flutter. This phenomena is not considered in the model. Several forces have been neglected in this model. Forces in the direction of the movement are neglected / not included in the model. The piston ring would be affected by pressure-forces on the sides from the gas pressure in $\mathrm{x}$-direction as well as friction force between the piston and piston ring in $\mathrm{z}$-direction. Both inertia and asperity contact forces of the piston ring have been neglected.

For each crank angle degree, $\theta$, an equilibrium between the forces is desired with the minimum film thickness, $h_{0}$, as the free parameter. The force equilibrium can be seen in Equation 6.

$$
F_{1, b s}^{\prime}+F_{s p}^{\prime}=F_{0}^{\prime}+F_{1, s s}^{\prime}+F_{2, s s}^{\prime}
$$

and

$$
F_{0}^{\prime}=\int_{l_{h y d}} p_{0} d x
$$

Where $F_{1, b s}^{\prime}$ is the back-side force from the pressure behind the ring, $F_{s p}^{\prime}$ piston ring tension force, $F_{0}^{\prime}$ hydrodynamic force together with $F_{1, s s}^{\prime}$ and $F_{2, s s}^{\prime}$ as the surface-side forces exerted by the gas pressures at the non-wetted length of the piston ring surface.

Several iterative methods exist to achieve the force equilibrium and the chosen one will be examined in the following section.

\section{Pertubation of Reynolds equation}

A method was suggested by [14] with perturbation of Reynolds equation. It has shown to be faster than the Newton-Raphson secant method. The height profile of the piston ring over the liner is based on an assumed parabolic geometry, $h=h_{0}+(1-\cos (\phi))$. It is then subjected to a perturbation with an infinitesimal disturbance of the height profile, $\Delta z$, so that $h=\left(h_{0}+\Delta z\right)+(1-\cos (\phi))$. It leads to a perturbation in the lubricant pressure distribution with $p=p_{0}+p_{\Delta} \Delta z$. Higher order terms are neglected. By completing the algebraic perturbation, Reynolds equation can be expressed with respect to the perturbation pressure, $p_{\Delta}$, as seen in Equation 7 where an approximate solution is found by FDM from [14].

$$
\frac{\partial}{\partial x}\left(h_{0}^{3} \frac{\partial p_{\Delta}}{\partial x}\right)=-3 \frac{\partial}{\partial x}\left(h_{0}^{2} \frac{\partial p_{0}}{\partial x}\right)+\frac{12 \eta_{0}}{\delta t}
$$

Where $h_{0}$ is the initial height, $p_{\Delta}$ the perturbed pressure, $p_{0}$ the initial pressure, $\eta_{0}$ the viscosity and $\delta t$ the timestep.

A coefficient, $K_{z}$, is introduced which can be found by integrating the perturbed pressure distribution over the wetted length, $K_{z}=\int_{l h y d} p_{\Delta} d x$. It can be considered as a dynamic coefficient of stiffness in the system and can be utilized in the search of force equilibrium by the relation of Equation 8.

$$
\begin{aligned}
& K_{z} \Delta z-\sum F_{z}^{\prime}=0 \\
& \Leftrightarrow \Delta z=\frac{F_{1, b s}^{\prime}+F_{s p}^{\prime}-F_{0}^{\prime}-F_{1, s s}^{\prime}-F_{2, s s}^{\prime}}{K_{z}}
\end{aligned}
$$

Where $K_{z}$ is the coefficient of stiffness, $F_{z}^{\prime}$ the forces in the z-direction, $F_{1, b s}^{\prime}$ the back-side force from the pressure behind the ring, $F_{s p}^{\prime}$ the piston ring tension force, $F_{0}^{\prime}$ the hydrodynamic force together with $F_{1, s s}^{\prime}$ and $F_{2, s s}^{\prime}$ as the surface-side forces exerted by the gas pressures at the non-wetted length of the piston ring surface.

So

$$
h_{0}^{n e w}=h_{0}+\Delta z
$$

Where $h_{0}^{\text {new }}$ is the new minimum film thickness, $h_{0}$ the old minimum film thickness and $\Delta z$ the infinitesimal disturbance of the height profile.

The new minimum film thickness from Equation 9 is inserted into the initial Reynolds equation in Equation 2 and the calculations start over again and a new estimate for the right minimum film thickness is found. This iterative procedure continues until the required change in the film thickness, $\Delta z$, is below a desired tolerance, $\Delta z_{\text {limit }}=10^{-9}$, so that $\Delta z<\Delta z_{\text {limit }}$. The implicit method has proven to be stable.

\section{Flow continuity}

The lubrication regime in the initial stroke along the liner can be both fully flooded, purely starved or a combination of both. To determine the effect of starvation the boundary 


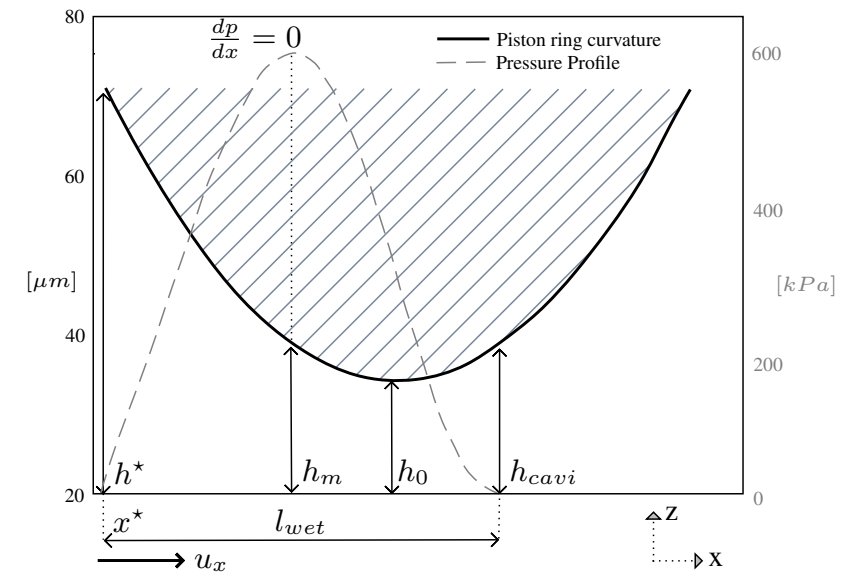

Figure 4. Piston ring curvature and pressure profile.

conditions should be set continuously for each stroke. The amount of lubricant left behind for the piston to encounter in the next stroke is found from the pure Couette flow with $h_{\text {out }}^{\infty}=\frac{h_{\text {cavi }}}{2}$ where it is assumed that $h_{\text {cavi }}$ is the oil film thickness at the point of cavitation with $\frac{\partial p}{\partial x}=0$ in Figure 4 and 5.

The starvation point and corresponding inlet height of the lubricant, $h^{\star}$, are found by applying flow continuity conditions through the gap between the liner and piston ring. The volume flow per unit length is formulated by $q_{x, \text { ring }}^{\prime}=\frac{u_{x} h^{\star}}{2}-\frac{\left(h^{\star}\right)^{3}}{12 \eta_{0}} \frac{\partial p}{\partial x}$ and the inlet boundary conditions as $q_{x, \text { in }}^{\prime}=u_{x} h_{i n}^{\infty}$ which is the lubricant left behind from the previous stroke. The inlet height of the lubricant is where $q_{x, \text { ring }}^{\prime}=q_{x, \text { in }}^{\prime}$ - see Figure 5 where the different shapes of the velocity profiles between the piston ring and liner can be seen. If flow continuity is not obtained the wetted length will be reduced, followed by a change in film thicknesses, pressure distribution, pressure gradients and the iterations start over again. A flow chart of the iteration process can be seen in Figure 6.

\section{Results and discussion}

In order for the solution to converge to the piston ring's force equilibrium, up to $\approx 160$ iterations were needed with severe starved conditions and as few as 2 iterations with fully flooded conditions. The time increment was set equivalent to $1^{\circ}$ of crankshaft angle. Figure 7 illustrates the typical computational costs throughout a stroke.

The values used to execute the simulations are shown in Table 1. A viscosity of $71 \cdot 10^{-3}$ Pas is chosen as it represents a commonly used lubricant in large two-stroke diesel engines, SAE50 $@ \approx 85^{\circ} \mathrm{C}$.

The volume flow and corresponding velocity profiles at different locations is shown in Figure 5. The film thicknesses at those locations are presented in Figure 8 and 9 for, respectively, fully flooded and starved conditions. For the fully flooded situation the film thicknesses are smooth and without any sudden changes. The minimum film thickness, $h_{0}$, is low at the top and bottom dead center as the piston

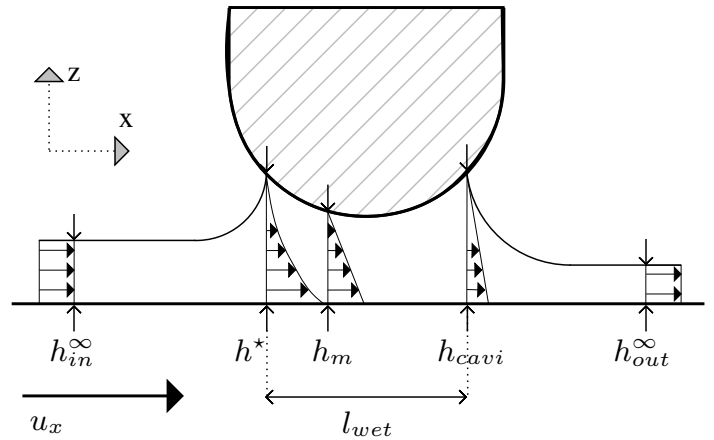

Figure 5. Volume flow on the piston ring surface.

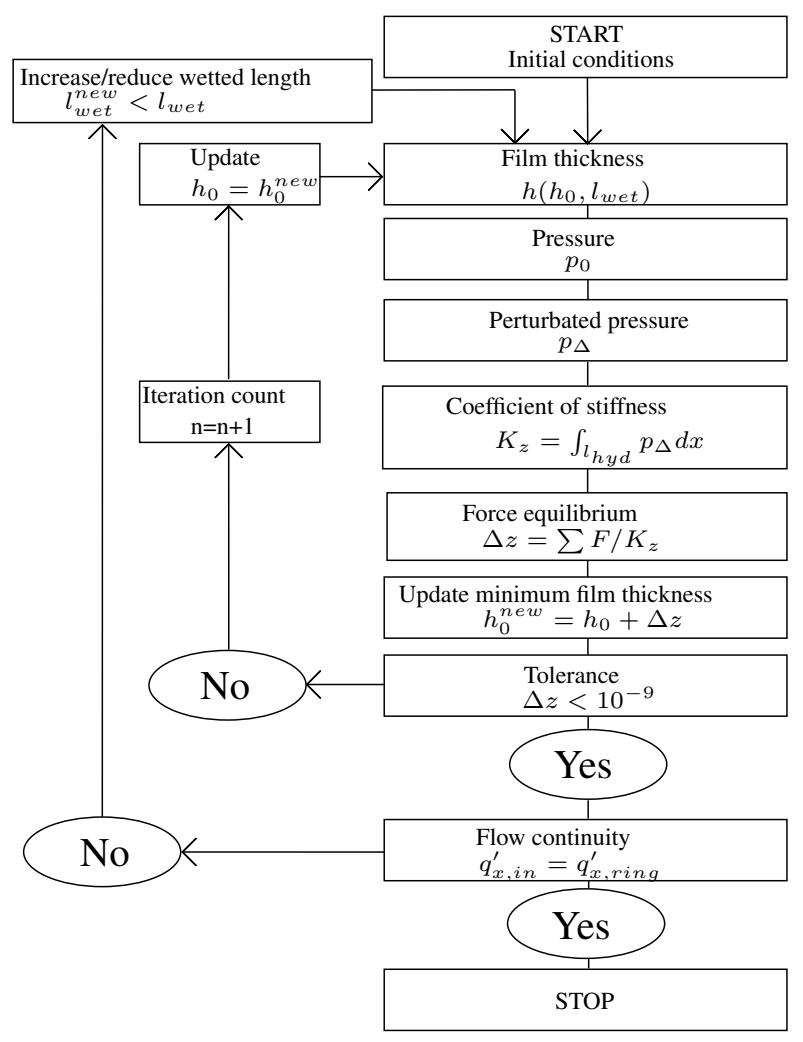

Figure 6. Flowchart of the iteration procedure.

ring velocity is low. A low velocity is corresponded by a high lubricant pressure and therefore a decrease in the film thickness is needed for maintaining the force equilibrium. As the required amount of lubricant is present at all time there will be no disruptions in the height increase of the piston ring.

The simulated starved conditions are shown in Figure 9. Initially, the film thicknesses are increasing smoothly as for the fully flooded conditions, but around $\theta=25^{\circ}$ lubricant 


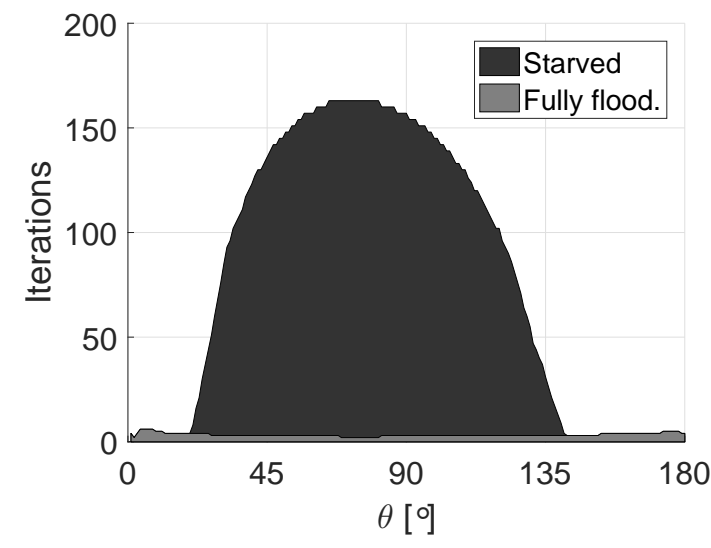

Figure 7. Computational costs. Piston ring curvature $r=100$ $\mathrm{mm}$.

Table 1. Values used for simulations.

\begin{tabular}{lll}
\hline Parameters & Value & Unit \\
\hline $\mathrm{D}$ & 0.5 & {$[\mathrm{~m}]$} \\
$\eta_{0}$ & 71 & {$[\mathrm{mPas}]$} \\
$\mathrm{I}_{0}$ & 5 & {$[\mathrm{~mm}]$} \\
$\mathrm{L}$ & 3 & {$[\mathrm{~m}]$} \\
$\mathrm{nx}$ & 400 & {$[-]$} \\
$\mathrm{p}_{1}$ & 0 & {$[\mathrm{~Pa}]$} \\
$\mathrm{p}_{2}$ & 0 & {$[\mathrm{~Pa}]$} \\
$\mathrm{p}_{s p}$ & 203 & {$[\mathrm{kPa}]$} \\
$\mathrm{r}$ & $100-300$ & {$[\mathrm{~mm}]$} \\
$\mathrm{R}$ & 1 & {$[\mathrm{~m}]$} \\
$\mathrm{N}_{\text {rev }}$ & 140 & {$[R P M]$} \\
\hline
\end{tabular}

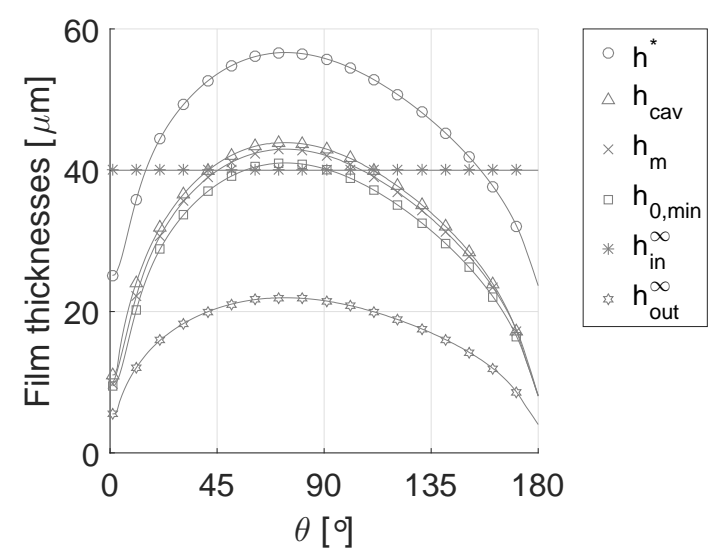

Figure 8. Different film thicknesses at fully flooded conditions. Piston ring curvature $\mathrm{r}=200 \mathrm{~mm}$.

starvation occurs. The wetted length of the piston ring surface is decreasing as the flow continuity point, $h^{\star}$, is moving towards the center of the ring followed by a decrease in the load carrying capacity. To overcome the reduced capacity and uphold the force equilibrium, the film thickness must decrease. This phenomenon is clearly seen in the Figure 8 vs 9 . The starvation will affect all of the different film thicknesses including the lubricant left behind, $h_{\text {out }}^{\infty}$, for the next stroke. An initial stroke with starvation will impact the following strokes.

The tendencies with respect to radii and the different terms of Reynolds equation are quite clear in Figure 10

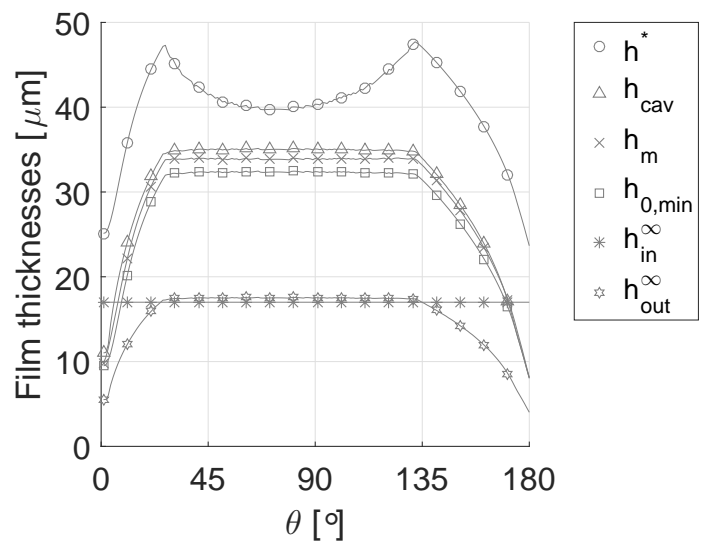

Figure 9. Different film thicknesses at starved conditions. Piston ring curvature $\mathrm{r}=200 \mathrm{~mm}$.

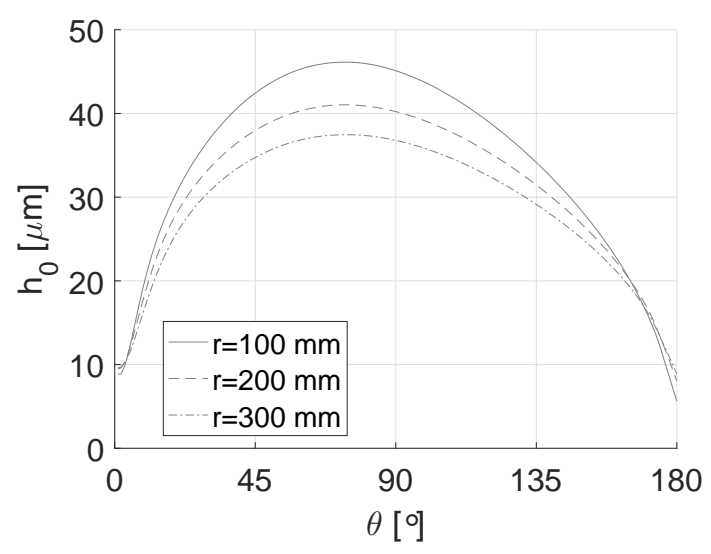

Figure 10. Minimum film thickness for fully flooded conditions. Different piston ring curvatures.

where the minimum film thicknesses are shown for fully flooded conditions at different radii. When observing the effect of piston ring curvatures at the mid-stroke for fully flooded conditions it can be seen that with a low radius the minimum film thickness will be fairly high but decreases with a higher radius. Low radii i.e. large curvatures together with high velocities makes the Couette term, in this case the physical wedge term, of Reynolds equation predominant in the mid-stroke which supports large film thicknesses. At the ends of the stroke the physical wedge term fades out due to the low velocities and the squeeze term of Reynolds equation becomes the predominant one. The squeeze term is most effective with two parallel surfaces and therefore high radii i.e. small curvatures have the largest load carrying capacity and thereby the highest film thicknesses at the ends of the stroke.

Regarding the starved conditions in Figure 11 it can be seen that the radii affect the point of where starvation occurs. The starvation is most significant with small radii and the film thicknesses will increase as the radii are increased. The behavior for starved conditions is different from fully flooded conditions. A smaller and finite amount of lubricant is available for the piston ring which enforces starved conditions. When increasing radii the starvation will be less significant which gives a larger wetted length on the piston ring surface. Hence, a larger film thickness is required for maintaining the load carrying capacities of large radii. The 


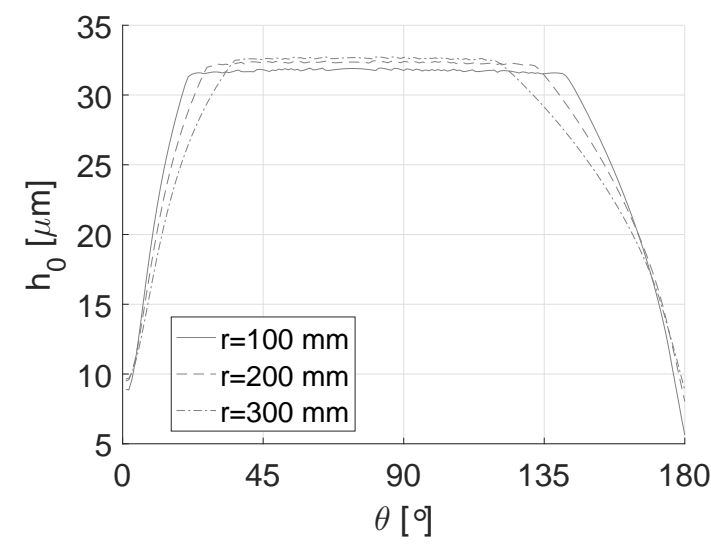

Figure 11. Minimum film thickness for starved conditions. Different piston ring curvatures.

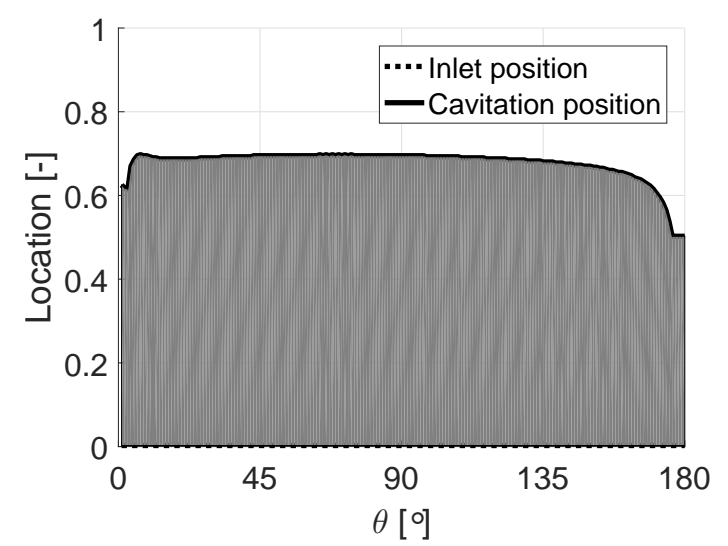

Figure 12. Position of inlet height and cavitation at fully flooded conditions. Piston ring curvature $r=100 \mathrm{~mm}$.

squeeze term predomination is once again seen at the ends of the stroke. Furthermore, the typical 'drops' in the film thicknesses are emphasized around $1-2^{\circ}$ just after the starting point of the piston with zero velocity. The piston ring squeezes a bit through the lubricant film, even though the velocity is different from zero, before the hydrodynamic pressure once again builds up.

The wetted length of the piston ring can be seen in Figure $12-15$ as the shaded area at different radii with both fully flooded and starved conditions where the inlet and cavitation positions are illustrated. It can be seen that in the situation with fully flooded conditions in Figure 12 the point of flow continuity is at the starting edge of the piston ring surface throughout the entire stroke. The simulations with starved conditions are seen in Figures 13,14 and 15. It can be seen that with increased radii starvation will be less significant and the point of flow continuity goes towards the edge of the piston ring.

The pressure history is illustrated in Figure 16-19 for both fully flooded and starved conditions at different radii. In the first stroke with fully flooded conditions the pressure is rather low as the wet and thereby load carrying length of the piston ring is large. During the starved strokes the wetted length will become larger and larger and therefore a smaller pressure is required to carry the same load with increased radii as mentioned previously. The mean pressures

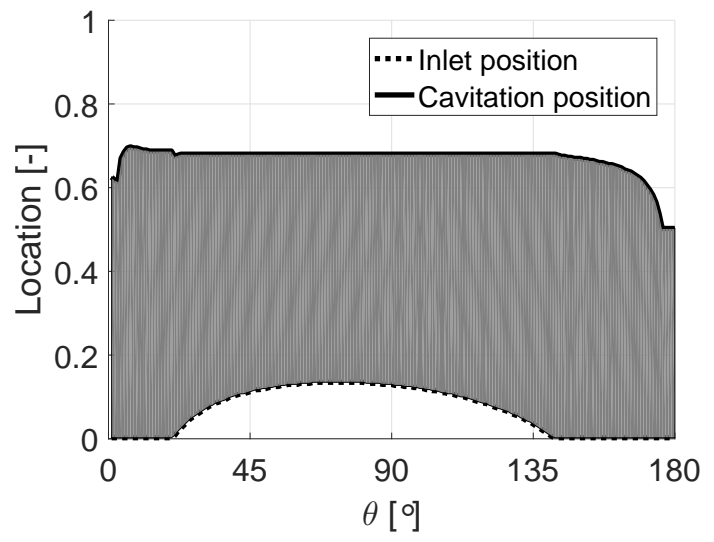

Figure 13. Position of inlet height and cavitation at starved conditions. Piston ring curvature $r=100 \mathrm{~mm}$.

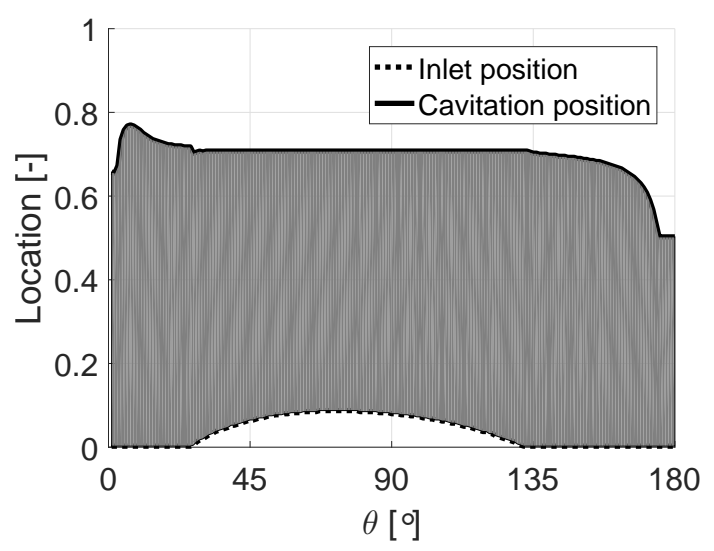

Figure 14. Position of inlet height and cavitation at starved conditions. Piston ring curvature $\mathrm{r}=200 \mathrm{~mm}$.

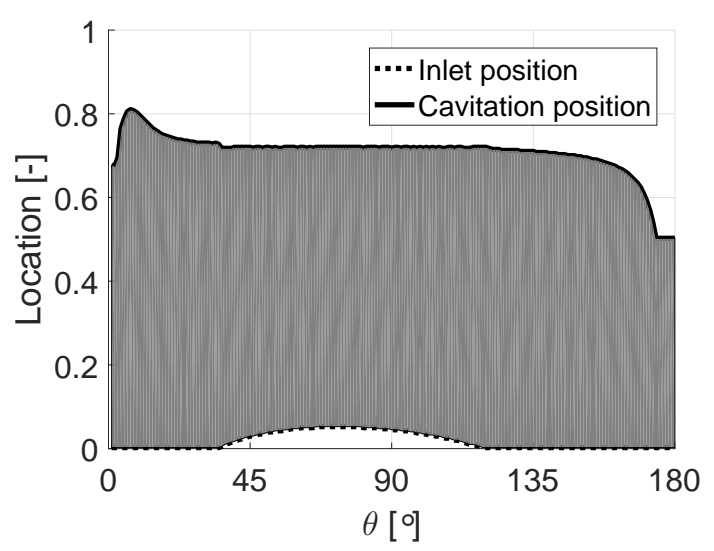

Figure 15. Position of inlet height and cavitation at starved conditions. Piston ring curvature $\mathrm{r}=300 \mathrm{~mm}$.

are illustrated by $p_{\text {mean }}$ in the figures. Furthermore, the relation between the load carrying capacity and the piston ring velocity is clear. Around top dead center and bottom dead center large pressures are needed as velocities are low.

The powerloss due to hydrodynamic friction forces can be seen in Figure 20. The frictional power loss has been found by considering the geometry of the piston ring. The viscous friction force is known to be dependent on the simulating parameters as the film thickness and the pressure gradient by $F_{\text {fric }}^{\prime}=\int_{0}^{l_{0}}\left[\frac{h}{2} \frac{\partial p}{\partial x}+\frac{u_{x} \eta_{0}}{h}\right] d x$ in [15]. For the starved 


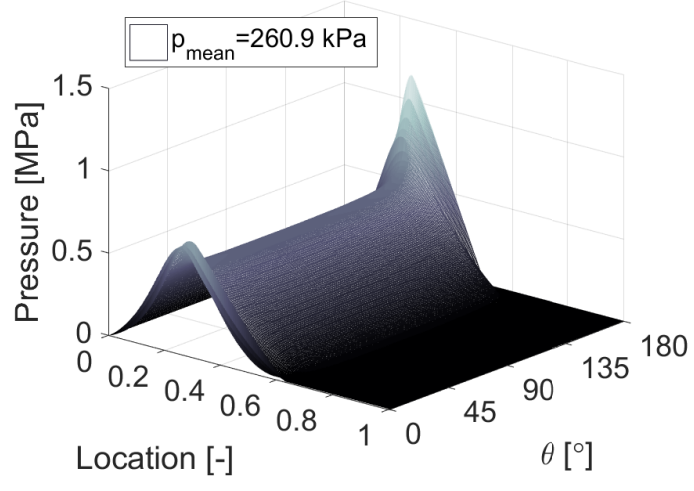

Figure 16. Pressure history at fully flooded conditions. Piston ring curvature $r=100 \mathrm{~mm}$.

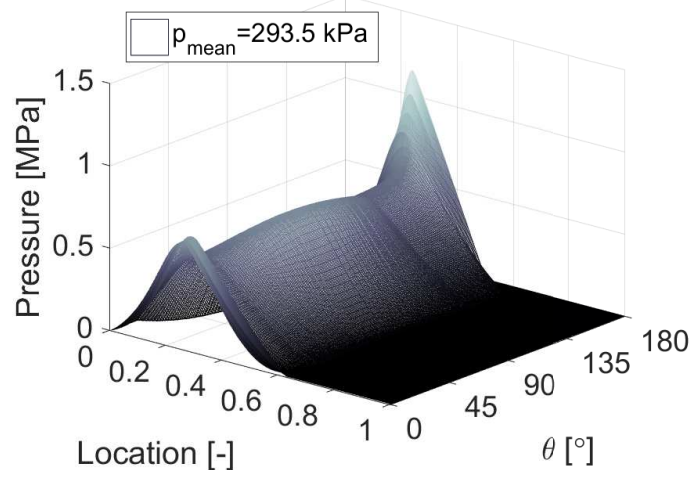

Figure 17. Pressure history at starved conditions. Piston ring curvature $r=100 \mathrm{~mm}$.

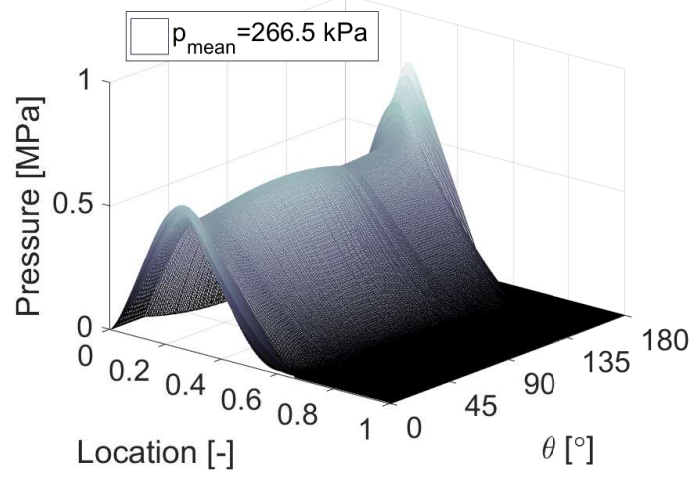

Figure 18. Pressure history at starved conditions. Piston ring curvature $r=200 \mathrm{~mm}$.

conditions the power loss is increasing with increased radii and corresponding increased film thickness as shown in Figure 11. The fully flooded conditions work opposite where the power loss also increases with increased radii but with decreasing film thicknesses. Even though the film thicknesses are decreasing with increased radii the power loss is still increasing. This shows the influence of the pressure gradient and the non-linearity in the viscous friction force.

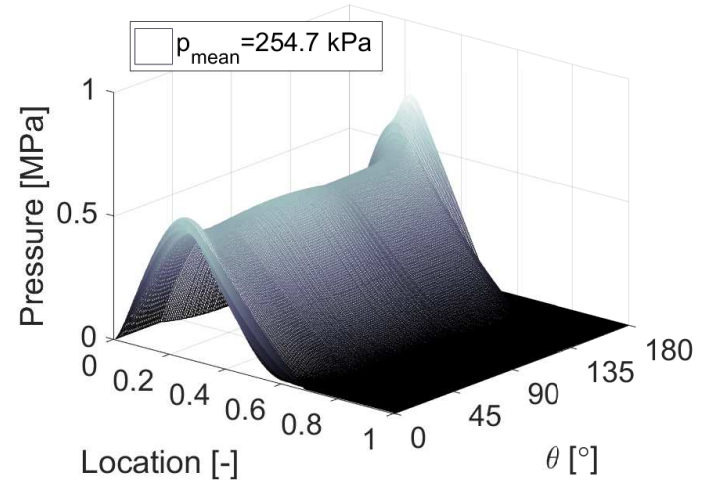

Figure 19. Pressure history at starved conditions. Piston ring curvature $r=300 \mathrm{~mm}$.

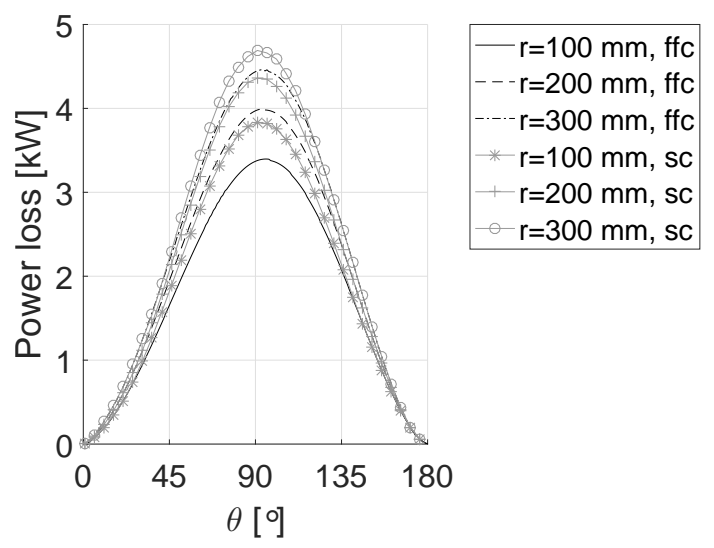

Figure 20. Frictional power loss at different piston ring curvatures for both fully flooded conditions (ffc) and starved conditions (sc).

\section{Conclusion}

(i) A proposal for a theoretical model to investigate the hydrodynamic lubrication of the top compression piston ring in a large two-stroke marine diesel engine has been made. The model has shown able to simulate a piston stroke both with fully flooded and starved conditions of the lubricant.

(ii) The behavior of fully flooded and starved conditions have shown to be different within the investigated range of radii. For fully flooded conditions with a theoretical infinite amount of lubricant the film thicknesses will be largest with small radii due to the effect of the wedge term.

(iii) During starvation with a limited amount of lubricant the model increases the wetted length of the piston ring with increased radii. Hence, the film thicknesses increase with increased radii for starved conditions.

(iv) The squeeze term has proven to have a beneficial effect in the model since the Couette term does not carry any load at the turning points of the piston ring.

\section{Funding}

The author(s) disclosed receipt of the following financial support for the research, authorship, and/or publication of this article: This project has received funding from the European Unions Horizon 2020 research and innovation program under grant agreement no. 634135 . 


\section{Declaration of conflicting interests}

The author(s) declared no potential conflicts of interest with respect to the research, authorship, and/or publication of this article.

\section{References}

1. Hamrock B J and Esfahanian M (1998), On the Hydrodynamic Lubrication Analysis of Piston Rings, Lubrication Science 104, August, p. 265-286.

2. Dellis P S (2010), Effect of friction force between piston rings and liner: a parametric study of speed, load, temperature, piston-ring curvature, and high-temperature, high-shear viscosity, Proceedings of the Institution of Mechanical Engineers, Part J: Journal of Engineering Tribology, 5, p. 411-426, 224.

3. Jeng Y-R (1992), Theoretical Analysis of Piston-Ring Lubrication Part I - Fully Flooded Lubrication, Tribology Transactions, 35, 4, p. 696-706.

4. Jeng Y-R (1992), Theoretical Analysis of Piston-Ring Lubrication Part II Starved Lubrication and Its Application to a Complete Ring Pack, Tribology Transactions, 35, 4, p. 707 714.

5. Gulwadi S D (2000), Analysis of Tribological Performance of a Piston Ring Pack, Tribology Transactions, 2, p. 151-162, 43.

6. Sanda S and Someya T (1987), The effect of surface roughness on lubrication between a piston ring and cylinder liner, Institution of Mechanical Engineers, p. 135-143, C223/87.

7. Ruddy B L and Dowson D and Economou P N (1981), A theoretical analysis of the twin-land of oil-control piston ring, Journal of Mechanical Engineering Science IMechE, 2, p. 51$62,23$.

8. Priest M and Dowson D and Taylor C M (2000), Theoretical modelling of cavitation in piston ring lubrication, Proc Instn Mech Engrs, p. 435-447, 214.

9. Vølund A and Klit P (2003), Measurement and Calculation of Frictional Loss in Large Two-Stroke Engines, Technical University of Denmark.

10. Abanteriba S (1995), Vergleich der Reibungsverluste eines Zweitakt-Kreuzkopf- und eines Viertakt-Tauchkolbenmotors gleicher Zylinderleistung, VDI Forschritt-Berichte, Nr. 151, Reihe 12

11. Lund J W and Thomsen K K (1978), A Calculation Method and Data for the Dynamic Coefficients of Oil-Lubricated Journal Bearings, The Design Engineering Conference, Topics in Fluid Film Bearing and Rotor Bearing System Design and Optimization, p. 1-12.

12. Han D C and Lee J S (1998), Analysis of the piston ring lubrication with a new boundary condition, Tribology International, 12, p. 753-760, 31.

13. Dowson D (1993), Piston Assemblies; Background and Lubrication Analysis, Tribology Series, C, p. 213-240, 26.

14. Lund J W (1990), Dynamic Coefficients for Fluid Film Journal Bearings, Vibration and Wear in High Speed Rotating Machinery, Kluwer Academic Publishers, p. 605-616.

15. Hamrock, B J and Schmid, S R and Jacobson, B O (2004), Fundamentals of Fluid Film Lubrication, CRC Press.
Table 2. Nomenclature.

\begin{tabular}{|c|c|}
\hline \multicolumn{2}{|c|}{ Parameters } \\
\hline D & Piston diameter, $[m]$ \\
\hline $\mathrm{F}^{\prime}$ & Force, $[N / m]$ \\
\hline $\mathrm{h}$ & Oil film thickness, $[m]$ \\
\hline$h_{0}$ & Oil minimum film thickness, $[\mathrm{m}]$ \\
\hline $\mathrm{h}_{\text {cavi }}$ & Oil film thickness at cavitation point, $[\mathrm{m}]$ \\
\hline $\mathrm{h}_{m}$ & Oil film thickness at $\partial p / \partial x=0$ \\
\hline K & Stiffness coefficient, $\left[\mathrm{N} / \mathrm{m}^{2}\right]$ \\
\hline$l_{0}$ & Piston ring length, $[\mathrm{m}]$ \\
\hline L & Connecting rod length, $[m]$ \\
\hline $\mathrm{N}_{\text {rev }}$ & Crankshaft rotational speed, $[R P M]$ \\
\hline$n x$ & Number of discretization points, $[-]$ \\
\hline $\mathrm{p}$ & Pressure, $[P a]$ \\
\hline$p_{1}$ & Gas upper pressure, $[\mathrm{Pa}]$ \\
\hline $\mathrm{p}_{2}$ & Gas lower pressure, $[\mathrm{Pa}]$ \\
\hline $\mathrm{p}_{s p}$ & Piston ring tension, $[\mathrm{Pa}]$ \\
\hline$r$ & Radius of curvature, $[\mathrm{m}]$ \\
\hline $\mathrm{R}$ & Crankshaft radius, $[\mathrm{m}]$ \\
\hline t & Time, $[s]$ \\
\hline $\mathrm{u}_{x}$ & Liner velocity, $[\mathrm{m} / \mathrm{s}]$ \\
\hline $\mathrm{u}_{p}$ & Piston velocity, $[\mathrm{m} / \mathrm{s}]$ \\
\hline \multicolumn{2}{|c|}{ Subscript } \\
\hline 0 & Initial \\
\hline bs & Back-side \\
\hline $\mathrm{cav}$ & Cavitation \\
\hline fric & Friction \\
\hline hyd & Hydrodynamic \\
\hline$i$ & Index \\
\hline in & From previous crank angle degree / stroke \\
\hline out & For next crank angle degree / stroke \\
\hline $\mathrm{sp}$ & Elastic spring tension \\
\hline sS & Surface-side \\
\hline wet & Wetted \\
\hline $\mathrm{x}$ & x-direction \\
\hline $\mathrm{z}$ & z-direction \\
\hline \multicolumn{2}{|c|}{ Superscript } \\
\hline$\sim$ & Mean \\
\hline$\infty$ & Outlet / inlet \\
\hline \multicolumn{2}{|c|}{ Greek letters } \\
\hline$\delta t$ & Timestep, $[s]$ \\
\hline$\Delta$ & Difference, $[-]$ \\
\hline$\eta_{0}$ & Absolute viscosity, $[\mathrm{Pa} s]$ \\
\hline$\omega$ & Crankshaft angular velocity, $[1 / s]$ \\
\hline$\theta$ & Crank angle degree (CAD), $\left[^{\circ}\right]$ \\
\hline
\end{tabular}

\section{Appendix}

The nomenclature is seen in Table 2. 